\title{
RETRACTION
}

\section{Retraction: Stimulation of the sacral nerve reduces gut bacterial translocation and endotoxemia caused by acute spinal cord injury in rabbits}

J-W Wu, J-Z Hu, X-Y Wang, H-B Lv and T-D Wu

Spinal Cord advance online publication, 18 May 2010; doi:10.1038/sc.2010.64

Retraction to: Spinal Cord advance online publication, 6 April 2010; doi:10.1038/sc.2010.35

The authors of the above article would like to retract it.

All the authors of the above article would like to retract this paper. The paper contains inaccuracies in four figures
(Figures $2 \mathrm{~b}$ and $\mathrm{c}$, and $5 \mathrm{a}$ and $\mathrm{b}$ ), which, although similar to the original images and containing the same message, are not the original pictures referring to the experiments performed. The authors apologize to the readers, reviewers and editors of Spinal Cord for publishing these erroneous images. 